\title{
REPLY TO HAYES
}

Hayes says I have a right to define stimulus equivalence in any way I like (though confusion may follow). Does he have a right to define equivalence in any way he wants to? I suggest not.

In my paper, I pointed out that, given a set, an equivalence relation may be defined in terms of reflexivity, symmetry, and transitivity, or in terms of a partition. Almost any text on set theory will point this out. Hayes, however, seems to think we should stick to the original meaning as used in the literature of stimulus equivalence (i.e., reflexivity etc.), and refers to this as Sidman equivalence. It might make more sense to call this Hayes equivalence, because Sidman and Tailby (1982, p. 6) specifically mentioned mathematics texts as the basis of their definition of equivalence. Given this, I am free to consult such texts and employ any other definition of equivalence that is generally accepted there.

Hayes also takes issue with the fact that I did not find derived functions, only directly trained functions. With my procedure, the question of derived versus directly trained, as Hayes defines those terms, is irrelevant. In another sense, however, the terms are relevant, and in that sense I did find derived functions. Suppose that, instead of two arbitrary subsets of 40 slides I had used green slides as Set 1 and red slides as Set 2 . With repeated reversals, if the birds had come to respond to later slides on the basis of the changed status of earlier slides, one could argue that little or nothing had been derived. In the case of my experiment, however, what the birds derived were the linkages (in some sense) between slides of a particular set, enabling them to partition the slides into two disjoint subsets.
Hayes' concern about the possible existence of equivalence relations in nonhumans is due to the suggestion, by him and others, that equivalence relations may in some sense underlie language functions in humans. For example, Wulfert and Hayes (1988) have recently stated that "such bidirectional relations among stimuli may provide a basis for referential meaning: The word is a symbol for the referent and the referent is the meaning of the word because both are members of the same equivalence class. In this sense, stimulus equivalence transforms nonlinguistic conditional discriminations into semantic process [sic] ..." (p. 126). In this case, the two relations are "is a symbol for" and "is the meaning of." If a word and its referent are to be members of an equivalence class, then at the very least the same relation must be shown to hold between them. I personally doubt that such relations exist in general, and therefore that equivalence relations underlie language in any basic sense, but I await the outcome of further research.

William Vaughan, Jr. Harvard University

\section{REFERENCES}

Sidman, M., \& Tailby, W. (1982). Conditional discrimination vs. matching to sample: An expansion of the testing paradigm. Journal of the Experimental Analysis of Behavior, 37, 5-22.

Wulfert, E., \& Hayes, S. C. (1988). Transfer of a conditional ordering response through conditional equivalence classes. Journal of the Experimental Analysis of Behavior, 50, 125-144. 